\title{
MÃES QUE ESTÃO EXPOSTAS A VULNERABILIDADE DOS FILHOS ADICTOS E O ADOECIMENTO PSICOSSOMÁTICO
}

\author{
Vânia Cristine de Oliveira ${ }^{1}$ \\ Gilmar Antoniassi Junior ${ }^{2}$
}

\section{RESUMO}

INTRODUÇÃO: O presente trabalho aborda acerca da possibilidade de adoecimento psicossomático em mulheres que se encontram expostas à vulnerabilidade, devido ao envolvimento com o uso de drogas por seus filhos, os quais estejam em atendimento no Centro de Atenção Psicossocial de Álcool e outras Drogas. Pretende-se evidenciar as queixas apresentadas; identificar sinais e sintomas de psicossomatização; e verificar a possibilidade do adoecimento psicossomático nessas mães de filhos adictos, considerando conflitos psíquicos, influências dos fatores emocionais e aspectos afetivo-emocionais manifestos de forma fisiológica por meio do desencadeamento e desenvolvimento de enfermidades. OBJETIVO: Verificar em mães de filhos adictos a possibilidade do adoecimento psicossomático quando expostas à vulnerabilidade do envolvimento das drogas. MÉTODO: Pesquisa de campo, do tipo qualitativo transversal, de natureza descritiva e exploratória. Utilizou-se como instrumentalização a Escala de Hamilton, Escala de Alexitimia de Toronto, Inventário de Estratégias de Coping de Folkman e Lazarus, e entrevista semiestruturada. A análise de dados consistiu em transcrição e categorização das entrevistas, e as escalas analisadas conforme padronização dos instrumentos. RESULTADOS: Percebeu-se fragilidade emocional e a divergência de sentimentos nos relatos das mães, quando expressam amor e zelo, ao mesmo passo em que manifestam fúria e desesperança, oscilando em suas relações com os filhos adictos, exprimindo um estado de adoecimento. Embora o instinto materno de cuidado e amor mantenha-se preservado, estas são tomadas por sentimentos conflitantes em virtude da presença das drogas, tendo a dinâmica familiar

\footnotetext{
${ }^{1}$ Acadêmica do curso de psicologia da Faculdade Patos de Minas - FPM. E-mail de contato: vania_cristine@hotmail.

${ }^{2}$ Mestre em Promoção da Saúde da Universidade de Franca - UNIFRAN - e docente do Departamento de Graduação em Psicologia da Faculdade Cidade Patos de Minas
} 

marcada por incompatibilidade nas relações e na comunicação. Através da instrumentalização, observou-se traços depressivos e alexítimicos, como a dificuldade de identificação e descrição de sentimentos e sensações corporais; assim como a utilização de algumas estratégias de enfrentamento para lidar com eventos estressantes. Verificou-se, portanto, a presença de adoecimento psicossomático em virtude da exposição a situações de vulnerabilidade envolvendo o uso de álcool e outras drogas. DISCUSSÃO: A presença de substâncias psicoativas é apontada como fator de maior risco e vulnerabilidade, e propensão às ações de violência, principalmente no meio familiar. As relações de mães com seus filhos adictos são, em sua maioria, norteadas por uma co-dependência dessas genitoras, uma vez que a exposição a comportamentos de risco de seus filhos as coloca em situação de sofrimento, culminando em adoecimentos psicossomáticos. CONSIDERAÇÕES FINAIS: Os efeitos e consequências da dependência química não se restringem apenas aos usuários da droga, mas afetam diretamente à sociedade, à família, e, sobretudo às mães. Faz-se necessário atribuir importância aos serviços de saúde pública e a necessidade de uma rede de apoio articulada que propicie a inserção e o envolvimento familiar, fornecendo tratamento especializado para adicto, bem como suporte de enfrentamento para a família.

Palavras-chave: Mães; Filhos; Drogas; Adoecimento; Psicossomático. 